\title{
TELENOVELA BRASILEIRA: UMA NARRATIVA SOBRE A NAÇÃO
}

\author{
Construção de sentidos sobre os discursos da vida pública e da \\ vida privada brasileira passam pela telenovela
}

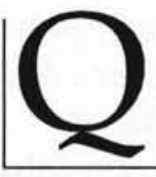

uase quarenta anos após a sua introdução, é possível afirmar que a telenovela ${ }^{1}$ no Brasil conquistou reconhecimento público como produto artístico e cultural e ganhou visibilidade como agente central do debate sobre a cultura brasileira e a identidade do país. Ela também pode ser considerada um dos fenômenos mais representativos da modernidade brasileira, por combinar o arcaico e o moderno, por fundir dispositivos narrativos anacrônicos e imaginários modernos e por ter a sua história fortemente marcada pela dialética nacionalização-massmediação.
A outra face desse processo foi o progressivo reconhecimento acadêmico da importância da telenovela como objeto privilegiado de estudo sobre a cultura e a sociedade contemporânea brasileira ${ }^{2}$. Esta situação peculiar alcançada pela telenovela brasileira é responsável pelo caráter, senão único, pelo menos muito peculiar, de uma narrativa nacional, popular e artística, além de se tornar tema de estudo consolidado. Este último aspecto não será objeto deste artigo, o qual se propõe a dar uma visão abrangente da importância alcançada pela telenovela na sociedade $\mathrm{e}$ na cultura do Brasil.

\footnotetext{
1. Telenovela é o nome genérico dado à narrativa ficcional televisiva no Brasil, independente de seu formato ser telenovela stricto sensu, minissérie, caso especial, ou outro. Neste artigo, também me referirei a ela como novela que é seu nome mais conhecido.

2. Os dados mostram um crescente interesse pela telenovela através de dissertações de mestrado e teses de doutorado, que passam de 6 na década de 70 , para 76 na de 90 , com média de aproximadamente 8 trabalhos/ano. As tendências principais nos estudos são: análise do discurso (abordagem semiótica, estética, intertextualidade, dramaturgia), estudos de recepção (abordagem sociológica, etnográfica), estudos de produção (som, cenografia, autores). $\mathrm{O}$ método de pesquisa mais freqüente tem sido o estudo de caso qualitativo de uma determinada telenovela ou uma determinada unidade de recepção (famílias, empregadas domésticas, metalúrgicos, jovens). Todo o levantamento de dados relativos à telenovela para o presente artigo foi feito no centro de documentação do Núcleo de Pesquisa de Telenovela, da Escola de Comunicações e Artes da Universidade de São Paulo.
} 


\section{TELENOVELA NO CENÁRIO TELEVISIVO BRASILEIRO}

A presença maciça da televisão em um país situado na periferia do mundo ocidental poderia ser descrita como mais um paradoxo de uma nação que, ao longo de sua história, foi representada, reiteradamente, como uma sociedade de contrastes acentuados, entre riqueza e pobreza, modernidade e arcaísmo, Sul e Norte, Litoral e Interior, campo e cidade. E, de fato, a televisão está implicada na reprodução de representações que perpetuam diversos matizes de desigualdade e discriminação. Mas, também é verdade que ela possui uma penetração intensa na sociedade brasileira, devido a uma capacidade peculiar de alimentar um repertório comum por meio do qual pessoas de classes sociais, gerações, sexo, raça e regiões diferentes se posicionam e se reconhecem umas às outras. Longe de promover interpretações consensuais mas, antes, produzir lutas pela interpretação de sentido, esse repertório compartilhado está na base das representações de uma comunidade nacional imaginada que a TV capta, expressa e constantemente atualiza ${ }^{3}$.

A televisão oferece a difusão de informações acessiveis a todos sem distinção de pertencimento social, classe ou região. Ao fazê-lo, ela torna disponíveis repertórios anteriormente da alçada privilegiada de certas instituições socializadoras tradicionais como a escola, a família, a igreja, o partido político, a agência estatal. A televisão dissemina a propaganda e orienta o consumo que inspira a formação de identidades. Nesse sentido, a televisão, e a telenovela em particular, é emblemática do surgimento de um novo espaço público, no qual o controle da formação e dos repertórios disponiveis mudou de mãos, deixou de ser monopólio dos intelectuais, politicos e governantes, dos titulares dos postos de comando da sociedade 4 .

Duplamente contraditório é o fato de este espaço público surgir sob a égide do setor privado, onde, não por coincidência, o produto de maior popularidade e lucratividade da televisão brasileira é a telenovela; e sob a égide da vida privada, uma vez que a

\footnotetext{
3. B. Anderson cunhou a noção "comunidade imaginada" para descrever a emergência dos Estados Nacionais na Europa do século XIX e associa a consolidação do sentimento de pertencimento a uma comunidade imaginária ao surgimento da imprensa escrita e das línguas nacionais. O ritual de leitura do jornal é apontado como exemplo de ritual que contribui para a consolidação desse sentimento de comunidade nacional. A noção é útil para entender o significado das telenovelas no Brasil, na medida em que o ato de assistir a esses programas num determinado horário, diariamente, ao longo de quase 40 anos, constitui um ritual compartilhado por pessoas em todo o território nacional, que dominam as convençōes narrativas consolidadas pela telenovela e que tomam os padrões nela mostrados como referenciais de acordo com os quais definem "tipos ideais" (no sentido weberiano) de familia brasileira, mulher brasileira, homem brasileiro e também de corrupção brasileira, violência brasileira, etc. Parece-me adequado usar a noção de comunidade nacional imaginada para indicar as representações sobre o Brasil, veiculadas pelas novelas $\mathrm{e}$ as maneiras como elas produzem referenciais importantes para a reatualização do conceito de nação e de identidade nacional. No caso brasileiro, trata-se, como veremos adiante, do fato paradoxal de a telenovela, uma narrativa ficcional, ter se convertido em um espaço público de debate nacional. C.f. ANDERSON, Benedict. Imagined communities (Comunidades imaginárias). Londres: Verso, 1991.

4. J. Meyerowitz sugere o deslocamento de repertórios de esferas restritas a homens ou mulheres, jovens ou adultos, como uma caracteristica importante da televisão. C.f. MEYEROWITZ, Joshua. No sense of place. Oxford: University Press, 1994.
} 
narrativa televisiva já foi definida como uma narrativa por excelência sobre a famílias.

\section{A novela dá visibilidade a certos}

assuntos, comportamentos, produtos e não a outros; ela define uma certa pauta que regula as interseções entre a vida pública e a vida privada ${ }^{6}$.

Vendo a telenovela a partir dessas categorias, podemos dizer que, durante $o$ período de 70 e 80 , ela se estruturou em torno de representações que compunham uma matriz capaz de sintetizar a formação social brasileira em seu movimento modernizante. Isto pode ser traduzido por um quase monopólio da representação social, calcada a partir das angústias privadas das famílias de classe média do Rio de Janeiro e São Paulo. Com a diversificação da estrutura da televisão (TV a cabo, vídeo, maior concorrência) e as modificações sociais e políticas em curso nos anos 90 (redemocratização política, novos movimentos sociais, processo de globalização), essa força de síntese do gênero desloca-se para novas representações que questionam as representações modernizantes anteriores.

\section{CONSOLIDAÇÃO DA INDÚSTRIA TELEVISIVA BRASILEIRA}

Desde os anos 70, pelo menos uma característica da indústria cultural brasileira resulta surpreendente por desmentir prognósticos feitos acerca de sua inescapável situação de dependência da produção cultural dos países mais industrializados. A produção de bens culturais tem apresentado crescente indice de nacionalização à medida que o mercado interno se expande. No início da década de 80 , cerca de $3 / 4$ da programação da TV já era nacional e hoje chega a quase $80 \%^{7}$. A nacionalização da produção se dá também no setor publicitário discográfico, editorial e de quadrinhos, sendo o cinema a grande exceção. Na produção de telenovela, dos 13 programas de ficção que estão atualmente no ar, nove (56\%) são nacionais e quatro (44\%) são importa$\operatorname{dos}^{8}$. Salientamos que a legislação brasileira sobre a comunicação de massa ainda proíbe o controle acionário de grupos econômicos estrangeiros nos meios de radiodifusão e imprensa ${ }^{9}$.

A televisão foi introduzida no Brasil em 1950 e, ao longo de seus cinqüenta anos de história, o Estado influiu de diferentes maneiras nessa indústria. Detém até hoje o poder de conceder e cancelar concessões de TV, embora sua política sempre tenha sido a de estimular o modelo comercial de TV, não ten-

5. Evocando o intelectual mexicano Carlos Monsiváis, a telenovela seria uma narrativa familiar sobre a nação, em que uma guerra é vista como um fato a partir do qual morreu um tio e uma cidade como um lugar onde mora um parente. 6. À telenovela aplica-se tanto o conceito de agenda setting como o de fórum cultural. C.f. NEWCOMB, Horace. La televisione da forum a biblioteca. Milano: Sansoni, 1999.

7. Pelas últimas estimativas, $79 \%$ da produção da TV Globo é de origem nacional.

8. Observação feita na Semana de 5 a 10 de novembro de 2001.

9. Foi aprovado na Câmara dos Deputados a Emenda Constitucional 203/95 que permite a entrada de até $30 \%$ de capital estrangeiro em empresas jornalisticas e de radiodifusão brasileiras. (N.E.d.) 
do havido, a rigor, até hoje, nenhuma experiência de televisão pública no país. Além de se apresentar como um grande anunciante dos meios de comunicação de massa, o Estado, particularmente a partir de 1964, durante o regime militar, tornou as telecomunicações um elemento estratégico na política de desenvolvimento, integração e de segurança nacional do regime. Além de aumentar o seu poder de ingerência na programação por meio de novas regulamentações, forte censura e políticas normativas, o governo militar investiu maciçamente na infra-estrutura, o que possibilitou a formação de redes nacionais (sistema microondas, satélite).

É sabido que a Rede Globo foi a maior beneficiária dessas políticas. Criada em 1965, essa rede cresceu rapidamente, movida por uma combinação de diversos fatores, como relações amistosas com o regime, sintonia com o incremento do mercado de consumo, uma equipe de produção e administração preocupada em otimizar o marketing e a propaganda, um grupo de criadores de esquerda vindos do cinema e do teatro.

Tendo crescido em consonância com outros processos estruturais de mudança ocorridos no período - a intensa migração do campo para as cidades (já em 1970, a população urbana superou a do campo), a industrialização e a proletarização do trabalho no campo, o desenvolvimento de um amplo mercado de consumo (se bem que vastamente concentrado nas classes médias e altas) -, a televisão, principalmente por meio das novelas, cap- ta, expressa e alimenta as angústias e ambivalências que caracterizaram essas mudanças.

A novela constitui-se em veículo privilegiado do imaginário nacional, capaz de propiciar a expressão de dramas privados em termos públicos e dramas públicos em termos privados.

É recorrente a mobilização da opinião pública em torno da curiosidade sobre as verdadeiras identidades dos personagens, traço característico da estrutura melodramática da novela (nascimento, caráter, desvios etc) com dramas públicos em termos privados (drogas, aids, trabalho infantil, movimento dos trabalhadores rurais, corrupção política etc.).

Utilizando uma estrutura narrativa personalizada e pouco definida em termos ideológicos ou políticos para tratar de assuntos relativos ao espaço público, as novelas levantaram e talvez tenham mesmo ajudado a dar o tom dos debates públicos. Tornaram-se dois exemplos históricos a associação da novela Vale tudo $(1988)^{10}$ à eleição de Fernando Collor de Melo, que calcou a sua imagem eleitoral como "o caçador de marajás", isto é, de banimento da corrupção econômica e política do país, bem como a influência da minissérie Anos rebeldes (1992) no processo de impeachment desse mesmo presidente, três anos depois.

10. Para economia de notação, todas as telenovelas citadas sem a emissora produtora são da TV Globo. 
As relações entre o Estado e as emissoras de televisão se modificam na década de 90 , quando o fim do regime militar e a redemocratização do país levam à suspensão das medidas de cerceamento de expressão e o mercado televisivo se segmenta com a introdução da TV a cabo e o acirramento da competição entre as redes de TV aberta ${ }^{11}$. A postura das emissoras é a de crescente independência de governos e partidos políticos, progressivamente baseada em mecanismos de mercado regidos pelas medidas das pesquisas de opinião e audiência, levadas a cabo por institutos como o IBOPE (Instituto Brasileiro de Opinião Pública e Estatística). Através delas, os profissionais de marketing, propaganda e de televisão constroem imagens da audiência e sintonizam emissores e receptores, garantindo uma dinâmica constante de captação e transformação das representações desses agentes.

\section{Telespectadores que se} formaram consumidores antes mesmo de cidadãos passam a constituir a unidade de referência desse mercado televisivo ${ }^{12}$.

Neste interessante aspecto a telenovela também parece funcionar como mediado- ra, pois ela pode ser vista através de um expressivo movimento pendular, tanto como uma vitrina de consumo (roupas, utensílios, casas, carros, estilos de vida, enfim) quanto um painel de temas sociais.

\section{ESTRUTURA DE PRODUÇÃO E PALIMPSESTO DA TELENOVELA}

A Rede Globo de Televisão é parte das Organizações Globo, principal conglomerado multimídia do país. Ela possui cerca de 8 mil funcionários, cobre $99,8 \%$ das cidades brasileiras, através de 113 estações afiliadas. Ao longo de sua história, a Globo criou um modelo empresarial de televisão que conseguiu vincular organicamente a administração, a produção e a comercialização dos seus produtos. Também conseguiu consolidar um cast (elenco) profissional e um star system (conjunto de estrelas) sob contrato exclusivo que, aliados a uma permanente atualização tecnológica, são responsáveis pelo padrão de qualidade de suas novelas e o conseqüente reconhecimento e fidelidade da parte do público. A partir de 1995, unificou toda a sua produção de teleficção na Central Globo de Produção, mais conhecida como PROJAC (Projeto Jacarepaguá, bairro do Rio de Janeiro). Ai trabalham 3 mil e 600 pessoas entre produtores, autores, diretores, atores, fotógrafos, editores, cenógrafos, iluminadores, sonoplastas, estilistas e modelistas. Concentramse ali os estúdios de gravação de todos os programas de ficção, a cidade cenográfica, os departamentos de construção de cenários

\footnotetext{
11. Esses fenômenos estão na base da queda de audiência da Rede Globo, mas não a ponto de perder a sua posição de "campeã absoluta de audiência". C.f. BORELLI, Silvia, PRIOLLI, Gabriel (coords.) A deusa ferida. São Paulo: Summus, 2000. Apesar da acirrada competição e mesmo perda de audiência em certos horários, a situação que ainda prevalece no panorama televisivo brasileiro é o do monopólio de audiência da Rede Globo, tal ainda é a distância em relação à segunda rede, o SBT (Sistema Brasileiro de Televisão). A média de share da Globo é de $40 \%$ e a do SBT é de $25 \%$. 12. A relação entre consumo e cidadania em nova chave de abordagem pode ser encontrada em CANCLINI, Garcia. Consumidores e cidadãos. Rio de Janeiro: Ed. UFRJ, 1995.
} 
e figurinos, de realização dos efeitos especiais e do centro de documentação e de registro de imagem. O sistema de produção do PROJAC é normalmente constituído pela gravação simultânea de quatro novelas, uma série (minissérie ou seriado) e um especial (produção episódica).

$O$ custo médio de uma novela de 180 capítulos é de 15 milhões de dólares, o que significa cerca de 80 mil dólares por capítulo. O capitulo diário possui, em média, 34 cenas gravadas, o que corresponde a $1 / 2$ filme de cinema. São 20 horas de gravação e 27 horas de edição para um capítulo de 45 minutos no ar. Normalmente, uma novela tem 60 a $70 \%$ de gravações em estúdio e de 30 a $40 \%$ de gravações externas. A produção envolve uma média de 200 pessoas e uma novela de sucesso alcança por volta de 45 pontos, representando uma média de 32 milhões de telespectadores e um share (porção de público total) de $58 \%{ }^{13}$.

\section{PALIMPSESTO DA FICÇÃO NA TELEVISÃO BRASILEIRA ATUAL}

Na televisão aberta existem hoje seis redes nacionais ${ }^{14}$, sendo que a disputa de audiência fica restrita entre a Globo e o $\mathrm{SBT}^{15}$, que são também as únicas que produzem ficção doméstica. O prime time (principal horário) da televisão brasileira foi padronizado pela Globo já na década de 70 , e pode ser resumido à seqüência: telejornal-telenovela-variedades (programa de auditório, humorístico ou game show).

O espaço atual da ficção televisiva é ocupado por 13 programas, sendo 10 telenovelas diárias e três séries semanais. Cada capítulo de novela possui em média 40 minutos brutos e cada episódio de série tem 30 minutos, o que dá uma média de sete horas diárias de ficção. Desses 13 programas, a Globo participa com oito, sendo sete produções novas e apenas uma reprise (no horário vespertino). A Globo não veicula telenovela estrangeira e todas as suas novelas são nacionais. Ao contrário, sua concorrente SBT participa apenas com uma produção nacional e quatro importadas (atualmente todas mexicanas).

O horário da novela foi uma criação da Globo, desde os anos 70, quando ela passou a produzir três novelas diárias. Esse horário se estende por uma faixa que vai das $17 \mathrm{~h} 30$ às $22 \mathrm{~h}$, sincronizou o horário de cada novela e acabou por determinar hábitos de assistência específicos ${ }^{16}$. A primeira faixa, das $17 \mathrm{~h} 30$, é ocupada por Malhação, única soap opera da TV brasileira dirigida para o público infanto-juvenil. Segue-se a no-

\footnotetext{
13. Entre as últimas novelas com maior share estão: Laços de familia (2000) 56\%; Porto dos Milagres (2001) 58\%, Terra nostra (1998) 59\% e $O$ clone também com $59 \%$.

14. Essas redes são: Gobo, SBT, Record, Rede TV!, Bandeirantes e Cultura. Todas são privadas à exceção da TV Cultura que é pública.

15. Ver nota 9.

16. O telespectador adquiriu o hábito de todo dia, numa determinada hora, assistir ao mesmo programa. O horário da novela é uma instituição na TV brasileira e costuma determinar a hora do jantar e até de dormir. As classes populares têm o hábito de dormir "depois da novela das oito", que continua a ser assim chamada apesar de atualmente ir ao ar das $2 \mathrm{lh}$ às $22 \mathrm{~h}$. Outro hábito criado é o de assistir ao principal telejornal do pais (Jornal Nacional, Globo, 20h15 - 20h55) que está ensanduichado entre duas novelas. Também é comum as pessoas marcarem seus compromissos noturnos para depois da novela. Finalmente, esse horário acabou conformando também a programação das demais emissoras que, no horário da novela, têm baixa audiência e acabam colocando no ar programas para serem sacrificados, mais do que verdadeiras alternativas às novelas. A disputa de audiência à faixa das novelas da Globo é movida, em primeiro lugar, pelo SBT, única concorrente da Globo que adotou a mesma lógica de programação exibindo no mesmo horário telenovelas, quase todas mexicanas. A segunda concorrência às novelas é movida pela TV paga.
} 
vela das seis, de temática geralmente histórica ou romântica; a novela das sete, de tema atual, em chave jovem $\mathrm{e}$ de comédia e a novela das oito, a principal, de tema social e adulto ${ }^{17}$. Entre a novela das $18 \mathrm{~h}$ e das $19 \mathrm{~h}$ vai ao ar um telejornal regional de 20 minutos e entre a novela das $19 \mathrm{~h}$ e a principal, há o mais assistido telejornal do país, com 40 minutos de duração. A lógica que preside a esse palimpsesto tornou-se clássica por combinar noticiário e me- lodrama, ficção e realidade, cuja contigüidade tem sido objeto de análises e estudos recorrentes.

Falar de telenovela brasileira é falar das novelas da Globo. São elas, sem dúvida, as principais responsáveis pela especificidade da teleficção brasileira. Essa especificidade é resultado de um conjunto de fatores que vão desde o caráter técnico e industrial da produção, passam pelo nível estético e artístico e pela preocupação com o texto e con-

\section{Grade de Programação da ficção televisiva brasileira *}

\begin{tabular}{|llll|}
\hline Emissora & Horário & Telenovela $-45^{\prime}$ & Origem \\
\hline Globo & $14 \mathrm{~h} 20-2^{\mathrm{a}}$ a $6^{\mathrm{a}}$ & A Gata Comeu & nacional \\
\hline Globo & $17 \mathrm{~h} 35-2^{\mathrm{a}} \mathrm{a} 6^{\mathrm{a}}$ & Malhação & nacional \\
\hline Globo & $18 \mathrm{~h} 05-2^{\mathrm{a}} \mathrm{a}$ sab & A Padroeira & nacional \\
\hline Globo & $19 \mathrm{~h} 15-2^{\mathrm{a}} \mathrm{a}$ sab & As Filhas da Mãe & nacional \\
\hline Globo & $20 \mathrm{~h} 55-2^{\mathrm{a}} \mathrm{a}$ sab & O Clone & nacional \\
\hline & & Série $-35^{\prime}$ & \\
\hline Globo & $22 \mathrm{~h} 45-3^{\mathrm{a}}$ feira & Brava Gente & nacional \\
\hline Globo & $23 \mathrm{~h} 15-5^{\mathrm{a}}$ feira & A Grande Familia & nacional \\
\hline Globo & $23 \mathrm{~h} 05-6^{\mathrm{a}}$ feira & Os Normais & nacional \\
\hline SBT & $17 \mathrm{~h} 15-2^{\mathrm{a}}$ a $6^{\mathrm{a}}$ & Preciosa & \\
\hline SBT & $17 \mathrm{~h} 35-2^{\mathrm{a}}$ a $6^{\mathrm{a}}$ & Rosalinda & mexicana \\
\hline SBT & $17 \mathrm{~h} 35-2^{\mathrm{a}}$ a $6^{\mathrm{a}}$ & Abraça-me Forte & mexicana \\
\hline SBT & $19 \mathrm{~h} 15-2^{\mathrm{a}}$ a sab & Carinha de Anjo & mexicana \\
\hline SBT & $19 \mathrm{~h} 15-2^{\mathrm{a}}$ a sab & Pícara Sonhadora & nacional \\
\hline
\end{tabular}

* Semana de 22 a $27 / 10 / 2001$

17. Seria necessário outro trabalho para analisar a novela do ponto de vista de sua realização como gênero e mostrar como ela veio se constituindo como um gênero híbrido, capaz de fundir no melodrama outros subgêneros como o cômico, o realismo fantástico, o drama, o romântico. Identificamos nesse gênero híbrido a base da teledramaturgia brasileira e um dos fortes motivos da preferência nacional de que é alvo a novela. Os outros motivos são a verossimilhança e as temáticas polêmicas. 
vergem no chamado padrão Globo de qualidade. É possível atribuir às novelas da Globo o papel de protagonistas na construção de uma teledramaturgia nacional ${ }^{18}$.

A atual grade de programação da ficção televisiva acima ilustra o que acabamos de descrever.

\section{TELEDRAMATURGIA NACIONAL OU EU VEJO O BRASIL NA NOVELA}

A consolidação da novela como o gênero mais popular e lucrativo da televisão está vinculada a uma mudança de linguagem, saudada pelos autores brasileiros com trabalho acumulado no rádio e no cinema. A oposição entre novelas realistas, críticas da realidade social, cultural e política brasileira, e novelas fantasiosas, ou dramalhões feitos para fazer chorar, marcou o debate entre os profissionais de novela, assim como a literatura sobre o tema e a opinião da audiência ${ }^{19}$. Para além dessa oposição, interessa marcar que, embora a versão fantasiosa, também conhecida como mexicana, procure se manter distante do comentário social e político e não admita o humor, a versão nacional, apesar de incorporar comentários sobre assun- tos contemporâneos, também se rege fortemente pelas origens folhetinescas do gênero.

A partir do final dos anos 60 e seguindo o modelo proposto pela Rede Tupi ${ }^{20}$, as novelas da Rede Globo se contrapuseram ao estilo fantasioso que dominava a produção anterior, propondo uma alternativa realista ${ }^{2 l}$. É a ruptura com o modelo representado pela novela Sheik de Agadir (Globo, 1966) -, com seus personagens com nomes estrangeiros, vivendo dramas pesados, diálogos formais e figurinos pomposos, ambientados em tempos e lugares remotos -, para o paradigma da novela brasileira que foi sendo construído a partir da novela Beto Rockfeller (Tupi, 1968). Este paradigma trouxe a trama para o universo contemporâneo das cidades grandes brasileiras, o uso de gravações externas, introduziu a linguagem coloquial, o humor inteligente, uma certa ambigüidade dos personagens e, principalmente, referências compartilhadas pelos brasileiros. Sintonizou as ansiedades liberalizantes de um público jovem, tanto masculino quanto feminino, recém-chegado à metrópole, em busca de instrução e integração aos pólos de modernização.

\footnotetext{
18. A história da telenovela começou na primeira emissora de TV, a extinta Tupi, responsável pela novela que foi o marco do abrasileiramento do gênero, Beto Rockfeller (1968). Em anos mais recentes, a Rede Manchete (que faliu em 1999) chegou a construir estúdios próprios e produziu algumas novelas que se equipararam às da Globo em qualidade de produção. Foram marcos de sua produção: Dona Beija (1986), Pantanal (1990) e Xica da Silva (1996), novelas que provocaram polêmica pelas cenas de nudez em suas tramas. Atualmente, é o SBT que constitui a segunda emissora em produção de telenovela. Construiu em São Paulo o Projeto Anhangüera, uma enorme área com estúdios e locações, mas que devido à sua produção irregular e descontinua, ainda não se constituiu em segundo pólo de produção teleficcional no pais.

19. Segundo pesquisa recente, $68 \%$ dos telespectadores nunca assistem a novelas produzidas em paises latino-americanos, como México e Colômbia. (pesquisa TGI - Target Group Index, outubro 2001).

20. A Rede Tupi foi a primeira rede de televisão do Brasil, marcou época como pioneira nos caminhos de uma dramaturgia própria da televisão com base em temas e personagens brasileiros. Com a sua falência, nos anos 70 , inicia-se a hegemonia da Globo.

21. ORTIZ, Renato et al. Telenovela: história e produção. São Paulo: Brasiliense, 1989. MATTELART, Armand, MATTELART, Michèle. O carnaval das imagens. São Paulo: Brasiliense, 1989.
} 
As convenções que passaram a ser adotadas daí em diante baseiam-se na máxima de que cada novela deveria trazer uma novidade, um assunto que a diferenciasse de suas antecessoras e fosse capaz de provocar o interesse, o comentário, o debate de telespectadores e de outras mídias, assim como o consumo de produtos a ela relacionados: livros, discos, roupas etc. Essa ênfase na representação de uma contemporaneidade sucessivamente atualizada é visível na moda, nas tecnologias, nas referências a acontecimentos correntes. Mas é visível também na evolução da maneira como o amor, o sentimento, o romance e a relação homem-mulher foram representados nas novelas dos anos 70 em diante.

Essa opção por uma definição clara no tempo e no espaço quase sempre a conjuntura contemporânea situada no âmbito da nação potencializa a vocação da novela de mimetizar e de constantemente renovar as imagens do cotidiano de um Brasil que se moderniza.

Isso pode ser identificado através dos dois planos estruturais de toda novela: $o$ renovado senso de exploração de temas contemporâneos e o verdadeiro efeito-demonstração dos padrões de consumo vi- vidos pelos personagens, os quais acenam para a população de espectadores com a possibilidade concreta de integração social por meio do consumo. Essa quase obsessão pela conjuntura e a moda é acomodada à estrutura seriada $\mathrm{e}$ interativa do folhetim e mobiliza repetidamente o gênero melodramático como matriz cultural e dispositivo de comunicabilidade ${ }^{22}$. As tramas das novelas são, em geral, movidas por oposições entre homens e mulheres; entre gerações; entre classes sociais; entre localidades rurais e urbanas; arcaicas e modernas, representadas como tendências intrínsecas e simultâneas da contemporaneidade brasileira. Outros recursos dramáticos típicos como identidades falsas, trocas de filhos, pais desconhecidos, heranças repentinas, ascensão social via casamento estão presentes de maneira recorrente e convivem bem com referências a temáticas e repertórios nacionais e atuais na época em que vão ao ar.

Alçada à posição de principal produto de uma indústria televisiva de grandes proporções, a novela passou a ser um dos mais importantes e amplos espaços de problematização do Brasil, das intimidades privadas às políticas públicas. Essa capacidade sui generis de sintetizar o público e o privado, o político e o doméstico, a notícia e a ficção, o masculino e o feminino está inscrita no texto das novelas que combinam convenções formais do documentário e do melodrama televisivo. É isso que mais tipifica a telenovela brasileira e constitui o paradoxo de se identificar o Brasil mais na narrativa ficcional do que no telejornal. São recorrentes nas novelas a identificação entre

22. MARTÍN-BARBERO, Jesús. Dos meios e das mediações. Rio de Janeiro: UFRJ, 1997. 
personagens da ficção e figuras públicas reais. Entre as tramas, os problemas reais e a tendência para uma maior verossimilhança nas histórias contadas, está, aliás, uma demanda forte do próprio público ${ }^{23}$. Tal combinação de gêneros e informações pode ser encontrada, por exemplo, no uso de documentários de época, inseridos nas seqüências de novelas desde Irmãos coragem (1970, novela de tempo atual) a Terra nostra (1998, novela de época). Ainda podemos mencionar a mais recente invasão de realidade na novela Porto dos Milagres (2001) pelo uso, no intervalo comercial, de clipes de campanha eleitoral com os personagens da novela, provocando o efeito de realidade de uma propaganda feita por partidos políticos verdadeiros. E, finalmente, a incorporação do noticiário, levada às últimas conseqüências, que passou a ser denominado de merchandising social ${ }^{24}$, em novelas recentes como a divulgação do trabalho das ONGs e a presença de mães de crianças desaparecidas ( $E x$ plode coração, 1995), o Movimento dos Sem-Terra e a presença de dois senadores da república em velório do senador da ficção (O Rei do gado, 1996), a doação de órgãos e a presença de médicos, explicando o câncer de uma jovem (Laços de família, 2000).

\section{TELENOVELA COMO OBRA ABERTA E OBRA DE AUTOR}

Fruto da combinação de profissionais de posições e intenções diversificadas, de dramaturgos e escritores de esquerda, passando por atores de talento a produtores e publicitários com visão de indústria e mercado, as novelas passaram a constituir o principal produto da Rede Globo, que a ajudaram a projetar-se como o maior conglomerado brasileiro de mídia, e competitivo em nível internacional $^{25}$. Pelo menos desde os anos 70, através da Globo, veio sendo consolidada uma série de mecanismos de produção e convenções de escritura e de recepção que configuram um sistema de real feedback na produção de um produto massivo. Esse sistema leva em conta a participação dos telespectadores no momento mesmo da produção. Nesse sentido, e porque vão ao ar enquanto estão sendo escritas, as novelas foram definidas como obras abertas $^{26}$. Elas são capazes de colocar em sintonia os telespectadores com a interpretação e a reinterpretação dos temas tratados.

A novela se tornou um veículo que capta e expressa a opinião pública sobre padrões legítimos e ilegítimos de comportamento privado e público, produzin-

23. São comuns as críticas tanto da mídia quanto do público a certas situações tratadas numa novela como sendo irreais e fantasiosas, cobrando mais realidade e menos ficção. Essa tendência ao realismo, ou mais precisamente, a uma naturalização das histórias contadas nas telenovelas talvez esteja na base dos mecanismos de legitimação e de credibilidade das novelas no Brasil. Sobre as relações entre ficção e realidade na telenovela brasileira, ver os trabalhos de: LOPES, Maria Immacolata Vassallo et al. Vivendo com a telenovela - recepção, mediações e ficcionalidade. São Paulo: Summus, 2002. MOTTER, Maria Lourdes. A telenovela: documento histórico e lugar de memória. Revista USP, 48. São Paulo: CCS/USP, 2001.

24. SCHIAVO, Marcio. Merchandising social: uma estratégia sócio-educacional para grandes audiências. Rio de Janeiro: Universidade Gama Filho, 1995.

25. O caráter de monopólio da televisão brasileira exercido pela Rede Globo é indiscutivel até hoje. Mesmo a guerra de audiência movida pela segunda rede, o SBT, é travada em alguns segmentos de horário, e principalmente em programas de auditório comandados pelo seu dono, Silvio Santos, que tem um percurso muito peculiar de self made man, de vendedor ambulante a empresário e dono do segundo conglomerado de midia no pais.

26. Alguns autores, como Renata Palottini, consideram a telenovela como obra em aberto. (N. Ed.) 
do uma espécie de fórum de debates sobre o país. São inúmeros os aspectos pelos quais se manifesta a construção dessa obra aberta. Eles se dão a partir da escolha do tema da novela em forma de sinopse, apresentada pelo autor (roteirista), revelando uma maior ou menor sensibilidade e afinidade com as demandas embrionárias ou explícitas no público. Este é o primeiro aspecto a ser avaliado em termos de possibilidade de a novela pegar em forma de audiência.

Os autores de novela são nacionalmente conhecidos pelos temas a que se dedicam, de modo que quando a próxima novela é anunciada em campanha de lançamento, o nome do autor é destacado ("novela de Benedito Ruy Barbosa") de modo a proceder à identificação do universo ficcional daquele autor. E o que pode ser esperado já passa a ser matéria de comentários em jornais, revistas, emissoras de rádio e televisão e, talvez mais importante, passa a ser conversado antecipadamente pelas pessoas ${ }^{27}$. Outro aspecto é a convenção de a novela ir ao ar quando somente 25 capítulos foram gravados, o que, segundo a produção, é uma média suficiente para o trabalho das gravações poder ser feito ao sabor das mudanças que se vão fazendo no roteiro. A produção também incorpora os indicadores fornecidos pela realização permanente de grupos de discussão realizados pelo setor de pesquisa da Globo.
Tudo leva a dar cada vez mais peso ao jogo da interação da novela e o público, a mobilização da empatia pelos conteúdos temáticos, formais e estéticos, onde tudo conta: a abertura, a história central, as tramas paralelas, os atores, os cenários, as músicas, os figurinos.

A avaliação é cotidiana, expressa-se quantitativamente nos índices de audiência, mas, principalmente, nos circuitos da circulação das conversas, dos quais falaremos adiante. Estas, além de evidenciar uma poderosa rede de produção e circulação de sentidos, expressam a verdadeira recepção da telenovela. Temos, portanto, uma captação quantitativa e formal da recepção dada através de índices de audiência e uma captação qualitativa e informal da recepção através da sua rede de circulação.

\section{TEMAS DA VIDA PÚBLICA E DA VIDA PRIVADA}

Eventos e temáticas sociais e políticas remetem à já citada discussão sobre o caráter crítico das novelas e as referências explícitas à nação.

Avançamos a hipótese de a novela exercer a função de agenda setting tal é

27. Os escritores de novelas são chamados significativamente de autores e não roteiristas. Cada autor tem uma equipe de dois a três escritores para desenvolver uma novela que tem em média 180 capitulos. Cada autor é conhecido por seu universo temático e pela composição dos personagens. Alguns chegam até a autoreferenciar-se quando, numa novela, o autor remete a personagens, lugares e situações por ele desenvolvidas em outra. Assim, Benedito Ruy Barbosa é conhecido como autor que trabalha com a temática rural; Aguinaldo Silva com a temática feminina e racial; Gilberto Braga é o cronista da classe média carioca; Manoel Carlos retrata o cotidiano da vida das grandes cidades; Sílvio de Abreu faz novela de humor com remessas cinematográficas; Lauro César Muniz dedica-se ao tratamento social critico; Glória Perez, às inovações de conteúdo polêmico etc. 
a agenda temática tratada. Questões como a reforma agrária, o coronelismo (o poder das oligarquias locais), a especulação imobiliária, as companhias multinacionais, a corrupção política, o racismo, as minorias, entre outras são alguns exemplos dessa vocação das novelas de incorporar temas do âmbito público em suas narrativas teoricamente voltadas para o universo privado. Mas temáticas como essas nas novelas são inseparáveis das temáticas do romance, da família, do amor, do casamento, da separação. É a lógica das relações pessoais, familiares que preside a narrativa dos problemas sociais. E aí parece residir o poder dessa narrativa, traduzir o público através das relações afetivas, ao nível do vivido, misturando-se na experiência do dia-a-dia, vivida ela mesma em múltiplas facetas, subjetiva, emotiva, política, cultural, estética etc.

A fusão dos domínios do público e do privado realizada pelas novelas lhes permite sintetizar problemáticas amplas em figuras e tramas pontuais e, ao mesmo tempo, sugerir que dramas pessoais e pontuais podem vir a ter significado amplo. Nesse sentido, são exemplares os casos da novela Barriga de aluguel (1990) que conta a história de uma inseminação artificial; de transplante de coração em De corpo e alma (1992); a destruição do meio ambiente em Mulheres de areia (1993); a chegada da internet em Explode coração (1995); a violência urbana em A próxima vítima (1995) e Torre de Babel (1998) e O clone (2001) com a clonagem humana.

Mas, talvez seja na trajetória das personagens femininas, assim como na das representações do amor e da sensualida- de, que se expressa de maneira mais bem acabada essa capacidade de aglutinar experiências públicas e privadas que caracteriza as novelas.

A primeira novela, ainda não diária, da televisão brasileira, Sua vida me pertence (Tupi, 1951), chamou a atenção por um beijo ardente. No começo dos anos 70 , o beijo ainda encarnava a sensualidade máxima nas novelas. Porém, ao longo dessa década, o ritmo das transformações na maneira como as novelas representaram os tipos ideais de mulher, de relações amorosas e de estrutura familiar acelerou-se. O privilégio do beijo seria rapidamente substituído por uma liberalização crescente das novelas que adentraram os aposentos íntimos dos personagens; cenários de quarto, casais na cama e gestos que simbolizam o orgasmo passaram a ser admitidos. Jogando com o universo proibido do incesto, da prostituição, do prazer, da nudez, do sexo antes do casamento, desvinculando-o da procriação, da separação como saída para casamentos infelizes, com a legitimidade de segundas uniões. Ainda, passou-se a tratar da vida profissional e independência financeira da mulher ${ }^{28}$, das tecnologias reprodutivas (Barriga de aluguel, 1990; O clone, 2001), da constituição de novos arranjos familiares em que uma mulher, mesmo solteira, decide criar filhos concebidos em relações diferentes (Laços de família, 2000). Entram em cena e são cada vez mais constantes os casamentos inter-raciais (Corpo a corpo, 1984; A próxima vítima, 1995; A indomada, 1996; Por amor, 1997; Suave veneno, 1999; Laços de família, 2000;

28. Na novela Laços de familia (2000), este tema foi tratado em forma de comédia, em que a superioridade profissional e financeira da esposa foi causa da impotência sexual no marido. 
Porto dos Milagres, 2001) e uniões homossexuais, seja entre homens jovens e adultos como entre mulheres (Vale tudo, 1985; A próxima vítima, 1995; Por amor, 1997; Torre de Babel, 1998) ${ }^{29}$. Outro índice da ampliação do espectro dos padrões de comportamento modernos, legitimados pelas novelas, é a introdução de romances entre mulheres mais velhas e homens mais jovens, o amor na terceira idade e um modelo de mulher profissional, liberada e independente, captando e expressando representações que quase sempre são mais avançadas em relação à realidade vivida. A recorrência com que os padrões desviantes de casamento e de sexualidade são tratados nas novelas fazem com que elas passem a conferir enorme visibilidade pública à discussão desses temas anteriormente tratados somente no âmbito privado. E, mais importante ainda, o tratamento realístico dado a esses temas não costuma escamotear os elementos de conflito e de preconceito, conferindo à novela alta credibilidade junto ao público.

É através desse efeito de credibilidade das novelas que elas colocam em circulação e em debate mensagens sobre a tolerância e o direito à diferença, a despeito do quase sempre "final feliz" dado a essas histórias.
E talvez o fascínio e a repercussão pública das novelas estejam relacionados a essas ousadias na abordagem dos dramas comuns de todo dia. Em que medida a moral final corresponde a modelos convencionais ou liberalizantes tem a ver com uma negociação simbólica ou dos significados em jogo. Negociação cheia de mediações que envolve autores, produtores, pesquisadores de mercado, instituições como a censura, a igreja, os movimentos negro, feminista, gay, ONGs e os diferentes públicos que vêem novelas. É certo que esses dramas nas novelas já não são lineares nem unilaterais, mas antes, bastante nuançados e marcados por um movimento ambivalente entre transgressão e conformismo. Com relação à questão da discriminação racial e sexista, o tratamento vem sendo crescentemente informativo, anti-dogmático e a favor da tolerância e do respeito às chamadas minorias. Neste aspecto, a novela parece configurar-se como uma linha de força na construção de uma sociedade multicultural no Brasil.

\section{PACTO DE RECEPÇÃO E TERRITÓRIOS DE CIRCULAÇÃO DE SENTIDOS}

Não resta dúvida de que a novela constitui um exemplo de narrativa que ultrapassou a dimensão do lazer, que impregna a rotina cotidiana da nação, construiu mecanismos de interatividade e uma dialética entre o tempo vivido e o tempo narrado e que se configura como uma ex-

29. Há que se mencionar que na novela Torre de Babel (1998), um casal de lésbicas foi retirado da história por provocar intensas manifestações negativas, principalmente na midia. Ficou famosa a solução dada pelo autor da novela em explodir o shopping onde elas, belas, liberadas e bem sucedidas, eram empresárias de moda. 
periência ao mesmo tempo cultural, estética e social. Como experiência de sociabilidade, ela aciona mecanismos de conversação, de compartilhamento e de participação imaginária. A novela tornouse uma forma de narrativa sobre a nação e um modo de participar dessa nação imaginada. Os telespectadores se sentem participantes das novelas e mobilizam informações que circulam em torno deles no seu cotidiano ${ }^{30}$.

As relações do público com as novelas são mediadas por uma variedade de instituições, pesquisas de audiência, relações pessoais, contatos diretos com autores, além da imprensa e da mídia especializada.

Tão importante quanto o ritual de assistir aos capitulos das novelas cotidianamente são a informação e os comentários que atingem a todos, mesmo àqueles que só de vez em quando ou raramente vêem a novela. As pessoas, independentemente de classe, sexo, idade ou região acabam participando do território de circulação dos sentidos das novelas, formado por inúmeros circuitos nos quais são reelaborados e ressemantizados.

\section{A novela é tão vista quanto}

falada e seus significados são o produto tanto da narrativa audiovisual, produzida pela televisão, quanto da interminável narrativa oral produzida pelas pessoas.

Como muitas pesquisas já mostraram, a novela começa a ser comentada durante o próprio ato de sua assistência. Conversa-se sobre ela em casa, com o marido, a mãe, os filhos, a empregada, com os vizinhos, os amigos, no trabalho. Fala-se dela nas revistas especializadas em comentários e fofocas sobre novelas; em colunas dos jornais diários, tanto os de prestígio quanto os populares; nas pesquisas de opinião feitas por institutos; nas cartas de leitores mandadas aos jornais e revistas; nos programas de televisão e rádio que acompanham as novelas tanto em forma de reportagem e entrevistas com seus atores, quanto em programas de humor nos

30. A partir de meados da década de 80 , diante da insatisfação com os trabalhos que se restringiam a interpretar o conteúdo ideológico de programas televisivos, ou priorizavam a análise político-institucional da indústria cultural, o foco dos estudos passou a recair sobre a recepção. A análise desses estudos extrapola os objetivos do presente texto. Limitamo-nos somente a ressaltar que o percurso desses estudos foi marcado por uma ampliação das referências teóricas e dos quadros metodológicos, em que se passou a adotar uma abordagem crescentemente complexa e interdisciplinar a ponto de a recepção não ser mais tratada como um pólo, mesmo que ativo, do processo de comunicação, como aparece na grande literatura internacional sobre o tema. Nos atuais estudos latino-americanos, a recepção aparece propriamente como uma perspectiva de análise, pela qual todo o processo de comunicação é reconstituído (produção, meio, texto e público). Parece que o termo "recepção" já não alcança mais para dar conta desse tipo de pesquisa, a que preferimos chamar de estudos de mediações. A nosso ver, são estes os que passam a ser uma marca distintiva das atuais pesquisas latino-americanas de comunicação. Esses estudos no Brasil começaram por discutir as diferenças de interpretação entre segmentos determinados do público, como a classe social e a situação geográfica, até chegar aos estudos mais atuais que demonstram o caráter interativo da novela, da construção de um repertório compartilhado sobre a nação, do pacto de recepção entre a produção e o público, numa dinâmica que ao longo dos anos consolidou convenções formais de narrativa que são de amplo dominio do público. As diferenças de interpretação das novelas nas diferentes regiões, classes e segmentos sociais só são possiveis porque todos vêem a novela. Como dissemos no início do presente texto, o significado sociocultural da telenovela no Brasil (e no restante da América Latina) para a modernidade que se vive na região, vai muito além de seus efeitos. E aqui parecem caber as férteis pistas abertas por estudos sobre as relações entre oralidade e visualidade, que vêem a televisão e, particularmente, a telenovela como dispositivos de reordenamento da cultura. C.f. MARTÍN-BARBERO, Jesús, REY, German. Los ejercicios del ver (Os exercícios do olhar). Barcelona: Gedisa, 1999. 
quais elas são satirizadas. A novela também aparece nas músicas dos CDs de trilhas sonoras que são especialmente compostas; em todo um circuito de merchandising que vai das roupas e jóias, usadas pelos atores, aos objetos de decoração, bebidas, carros, lojas e bancos que aparecem nas histórias; e nos comerciais com os atores das novelas que estão no ar.

Os autores declaram expressamente à imprensa que procuram pessoas na rua para saber as suas opiniões sobre o que estão escrevendo para assim ter idéias sobre o desenvolvimento dos personagens. As gírias e maneirismos usados por certos personagens são incorporados rapidamente na linguagem do dia-a-dia; nomes de personagens entram em moda e crianças são batizadas com eles; nomes de novelas passam a ser nomes de padarias e lojas; também nomes de alguns personagens são usados como adjetivos para designar o caráter desviante de pessoas.

Além disso, situações vividas por um personagem na novela ou as características de seu caráter podem ser objeto de mobilização de sindicatos, do movimento negro ou gay, de políticos, de comunidades étnicas que criticam ou reivindicam mudanças em situações e personagens que contrariam a sua imagem pública ${ }^{31}$. As novelas ainda podem ser encontradas refletidas nas propostas de projetos de lei para o estabelecimento de quotas para atores negros e disciplinando o trabalho de atores infantis e adolescentes. Freqüentemente, as tramas das novelas provocam a discussão da necessidade de códigos de ética por parte das emissoras de TV, seja em forma de lei ou de auto-regulamentação.

$\mathrm{E}$, finalmente, as novelas provocam a torcida por personagens que se encontram em confronto ou sobre o que elas devem fazer ou sobre a mudança que deve haver no seu comportamento. O mais novo espaço ocupado por toda essa conversação que a novela provoca é a internet, onde cada novela tem seu site (informado ao final da ficha técnica que encerra cada capítulo diário), e as opiniões se expressam em inúmeras listas de discussão ${ }^{32}$.

A força e a repercussão da novela mobilizam cotidianamente uma verdadeira rede de comunicação, através da qual se dá a circulação dos seus sentidos e provocam a discussão e a polêmica nacional.

Através desse fórum de debates capilarmente difuso, complexo e diversificado, as pessoas sintetizam experiências públicas e privadas, expressam divergências e convergências de opinião sobre ações de personagens e desdobramentos de histórias. O caráter de repertório compartilhado permite a manifestação de diferenças, a expressão das competências sobre o gê-

31. As manifestações públicas quase sempre vão no sentido de criticar as novelas por discriminação (pelo tratamento indevido a personagens negros, gays, mulheres, crianças), por difamação (por exemplo, politicos ou figuras públicas que se sentem atingidas), por realçar traços negativos de categorias profissionais (como policiais, advogados, médicos, jornalistas, empresários de multinacionais etc.).

32. Como exemplo deste fórum recente, um jornal promoveu uma discussão baseada em uma reportagem em que se identificava o "branqueamento" dos personagens numa novela recente, Porto dos Milagres (2001), baseada em romance de Jorge Amado, cujos personagens são majoritariamente negros. 
nero, de domínio das convenções dramatúrgicas da telenovela, da sensibilidade do olhar que cerca os detalhes, seja nos cenários e nos figurinos, seja nos múltiplos plots (linha de ação, núcleo dramático) que se entrelaçam no emaranhado de 200 capítulos para, ao fim, emitir seu julgamento sobre diversos finais dessas tramas. Critica-se ou aplaude-se a produção pela condução da obra.

Quando uma novela galvaniza o país, nesse momento ela atualiza seu potencial de sintetizar o imaginário de uma nação, isto é, a sua identidade, ou o que é o mesmo, de se expressar como nação imaginada.

Esta representação, ainda que estruturalmente melodramática e sujeita à variedade de interpretações, é aceita como verossímil, vista e apropriada como legítima e objeto de credibilidade. Há um consenso na literatura em denominar esse imaginário como moderno, uma vez que as novelas movimentam os imaginários modernos da nação sobre alguns eixos temáticos recorrentes e que, em síntese, são: a mobilidade social, a nova família, a diversidade sexual, étnica, racial, a afirmação feminina, a renovação ética.

No mínimo é irônico que um programa inicialmente classificado pela indústria como entretenimento dirigido às mulheres de nível socioeconômico $\mathrm{C}$ tenha dominado o horário nobre da televisão brasileira e se transformado num fórum de debates sobre a nação, compartilhado por um públi- co nacional composto por mulheres, homens e crianças em todos os grupos sociais e locais do território nacional. A novela talvez seja um exemplo único de como um sistema de mídia televisivo pode ser responsável pela emergência de um espaço público peculiar que nos anos atuais se diversificou e se apresenta como alternativa principal de realização pessoal, inclusão social e de poder, isto é, como uma nova forma de cidadania. A novela, enfim, conseguiu permeabilizar o espaço público brasileiro à atualização e à problematização da identidade nacional em um período de profundas e aceleradas transformações.

\section{DO ESPAÇO AUDIOVISUAL NACIONAL PARA O TRANSNACIONAL}

Como vimos, o que tem tornado a telenovela um enclave estratégico para a produção audiovisual brasileira é o seu peso no mercado televisivo tanto quanto o papel que ela joga na produção e reprodução das imagens que os brasileiros fazem de si mesmos e através das quais, se reconhecem. Só este fato é suficiente para tornar indispensável a reflexão sobre os diferentes sentidos da telenovela no plano nacional. É este o objetivo que moveu o presente artigo. Porém, não queremos concluí-lo sem deixar de, pelo menos, apontar e reconhecer também a sua importância regional e transnacional.

Estruturada no Brasil, e também na América Latina, nos anos 60 e 70, a telenovela foi um fator determinante na criação de uma $\mathrm{ca}$ pacidade televisiva nacional que se projetou não só numa extensiva produção como também numa particular apropriação do gênero, isto é, sua nacionalização. Entretanto, isso vai além de modelar o caráter nacional da te- 
lenovela. Duas dinâmicas diferentes, mas intimamente conectadas, estão envolvidas: uma delas empurra para a integração do espaço latino-americano e outro mobiliza o mercado mundial. Dentro da América Latina, a telenovela conta com a vantagem de um longo processode identificação massiva e popular, colocada em movimento desde os anos $40 \mathrm{e}$ 50 , resultando no que se poderia chamar de um processo de integração sentimental dos países latino-americanos - uma estandardização de modos de sentir e de expressar, de gestos e sons, ritmos de dança e de cadências narrativas - tornada possível pelas indústrias culturais do rádio e do cinema ${ }^{33}$. Isto quer dizer que, enquanto marco nesta dinâmica de integração - os países em sua pluralidade nacional e diversidade cultural - a telenovela é também o lugar de intervenção da dinâmica da globalização do mercado mundial.

\section{A internacionalização da} telenovela responde ao movimento de ativação e reconhecimento do que é especificamente latinoamericano num gênero televisivo que começa a exportar sucessos nacionais.

Contraditoriamente, sua internacionalização também responde ao movimento de progressiva neutralização das características de uma latino-americanidade em um gênero que a lógica do mercado mundial pretende converter em transnacional no momento de sua produção. As co-produções são recentes na América Latina. Enquanto a Globo se associa à Telemundo, segunda rede hispânica dos Estados Unidos e braço da Sony Pictures Entertainment para fazer co-produções destinadas exclusivamente ao mercado externo, o SBT também está tratando de co-produzir com a Univisión dos Estados Unidos, associada da mexicana Televisa. Neste aspecto, o Brasil fez história com a exportação de telenovelas da Globo que alcançaram índices notáveis de audiência em inúmeros países da Europa e da Ásia - caso de A escrava Isaura, Dancing days, Roque Santeiro e até a recente Terra nostra. Por outro lado, a Televisa, do México, concentrada mais na América Latina e na audiência hispânica dos Estados Unidos, também alcançou enorme êxito com Os ricos também choram e Simplesmente Maria.

$\mathrm{Na}$ Europa, em anos recentes, o reordenamento dos sistemas nacionais de televisão européia, a privatização e expansão de canais e a introdução do sistema por cabo e satélite ampliaram enormemente a programação e abriram o mercado à internacionalização de telenovelas de outros países latino-americanos como a Venezuela, Argentina e Peru. A entrada das telenovelas latino-americanas no mercado audiovisual mundial certamente mostra o nível de desenvolvimento atingido pela indústria da televisão nesses países e também significa, em alguma medida, o rompimento da linha demarcatória entre o Norte e o Sul enquanto países considerados a ser produtores e os considerados a ser exclusivamente consumidores ${ }^{34}$. 
São desafios que se colocam num mercado televisivo hegemonizado, mas também fragmentado e segmentado em seu consumo e complexificado pelo aparecimento de novos atores sociais e novas identidades coletivas. Desafios em que convivem pro- cessos ambivalentes como a tendência a dissolver as diferenças culturais e a indiferenciação das audiências, por um lado, e, por outro, a tendência à migração e à afirmação em outros territórios de gêneros nacionais, como a telenovela brasileira.
Resumo. $\mathrm{O}$ artigo destaca a telenovela brasileira como produto cultural televisivo que ganhou expressão própria ao constituir-se como uma narrativa sobre as temáticas do cotidiano urbano e as questões sociais emergentes no Brasil. Destacando-se, desta maneira, das demais produções ficcionais e constituindo-se inclusive em produto de exportação. Como obra aberta, dá espaço à participação dos telespectadores, fazendo do autor/dramaturgo um profissional em constante interação com seu público. A infraestrutura de produção exigida faz da Rede Globo de Televisão a maior produtora de ficção televisiva do Brasil e uma das maiores do mundo. A autora dá números da significativa produção, fala sobre a formação de uma grade de programação que acabou por cristalizar um certo hábito de assistir à televisão, formando uma rede de circulação e constituição de sentidos sobre as temáticas da vida pública e privada brasileira.

Palavras-chave telenovela brasileira, narrativa, nação, Rede Globo, ficção, teledramaturgia
(The Brazilian telenovela: A narrative about the Nation)

Abstract. The article highlights the Brazilian telenovela as a television cultural product that gained its own expression by constituting itself as a narrative on daily life urban themes and about emergent social issues in Brazil. In this manner, it differentiates itself from the other fictional productions and is constituted as a product for export. As open work, this production opens space to viewer participation, transforming the author/ dramaturge into a professional who is in constant interaction with his or her public. The production infrastructure that is required tums Rede Globo de Televisão into the biggest fiction television producer in Brazil and into one of the biggest in the world. The author provides numbers regarding this significant production, talks about the formation of a major programming that ended up crystallizing a certain television watching habit, concretizing a network that circulates and constitutes senses regarding the themes that surround Brazilian public and private lives.

Key words. Brazilian telenovela, narrative, nation, Rede Globo, fiction, tele-dramaturgy 